\title{
Food Hubs: Reconnecting Alternative Food Networks and the Conventional Food Supply Chain
}

\author{
Michela Felicetti ${ }^{1, a}$ \\ ${ }^{1}$ Università telematica e-Campus, via Isimbardi. Novedrate (CO)- Italy. \\ amichela.felicetti@uniecampus.it
}

Keywords: Food Hubs, Agro-Food Districts, Supply Chains.

\begin{abstract}
This paper considers whether it is possible to apply the concept of food hubs to the area of Piana di Sibari in Calabria, which has been established by regional law as a Quality Agrifood District (Distretto Agroalimentare di Qualità or DAQ).

After identifying some features of the food hub concept in the biggest cooperative of the context, the paper will highlight how this situation represents an opportunity for small farmers to access conventional food supply chains from which they would otherwise be excluded.

In this view, food hubs are a mixture of alternative and conventional food networks and constitute a way to solve the problem of economic viability of local food initiatives like community supported agriculture.
\end{abstract}

\section{Introduction: The food hub concept.}

In the scientific literature some agrifood practices, such as community supported agriculture or farmers' markets, have been contrasted with conventional, industrial and global agrifood systems [1,2].

This literature has shown that the former, unlike the latter, are sustainable from a social, environmental and economic viewpoint. However, some studies have questioned the economic sustainability of such practices [3]. Thus food hubs contain the potential to economically support small and medium size enterprises through aggregation processes which facilitate economies of scale.

These arise when the food hub is based on aggregation and distribution enables a number of producers to put their products together and sell them in larger volumes than small producers could achieve by themselves.

The key to the food hub consists of a management team which coordinates supply chain logistics. Some food hubs focus on the supply side in order to support and train producers on sustainable agriculture practices, packaging techniques, certification, and food security. At the same time food hubs can also focus on the demand side by coordinating their work with other distributors, processers and wholesalers and also consumers, in order to meet the growing demand for local or regional produce [4].

Many farmers are penalised by the lack of distribution and processing infrastructure which would give them access to the retail sector and to food markets generally.

For large-scale producers food hubs can guarantee product differentiation strategies which ensure the highest possible market price.

For wholesalers, distributors, retailers and sellers of food produce who wish to buy larger volumes of local or regional produce, food hubs lower transaction costs by offering a single sales point.

Some food hubs are simply local food distributors, but generally they are much more than this: they are innovative business models which aspire to be financially sustainable and at the same time to have a positive impact on the community from the economic, social, and environmental viewpoint.

From an environmental viewpoint food hubs may work closely with producers to provide technical assistance to encourage the use of sustainable production practices in the field of pest management.

Food hubs are generally classified either by either their structure or their functions. Classifying food hub by their structure generally means looking at their business structure which may include: non- profit organizations, corporate structure, cooperatives or public held food hubs. The figure 1 below shows the categorization of regional food hub based on the 2012 report of the United States Department of Agriculture [5]. 


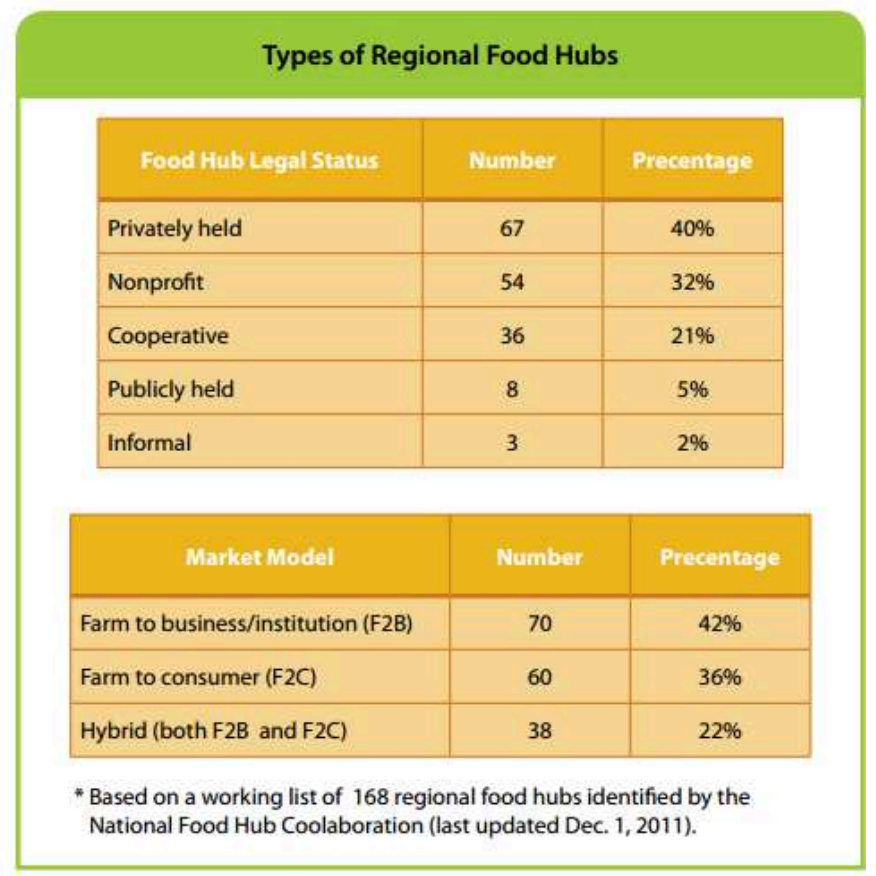

Fig. 1 - Types of Regional Food Hub according to the United States Department of Agriculture [5].

\section{The context of Piana di Sibari and the agrifood district.}

The case study is represented by an agrifood district covering 32 municipalities, over a surface area of 185 thousand hectares with more than one hundred agricultural firms working in a consortium.

Piana di Sibari is characterised by agricultural and agrifood specialisation which includes a great number of typical and quality-marked products, such as citrus fruits, olives, fruit and vegetables, dairy and meat.

In Piana di Sibari there is no urban focal point which in terms of size, geographic location, quality, or complexity in terms of development and functions to act as a driver for the economy and local organisation. To this may be added a lack of social urban services and a dissipation of territorial, landscape, and environmental capital and a significant dispersion of the population over the area.

In the cities and urban areas of Calabria there are almost never any manufacturing and tertiary activities, offices of the public administration, interchange points, and commercial activities of major retailers. Facilities and collective services are found scattered at random, often in peripheral, decentralised areas which are poorly served by public transport systems.

The Agrifood District of Sibari contains $96 \%$ of the surface area dedicated to citrus fruit growing in the whole province of Cosenza and around 33\% of that of the Region of Calabria.

Table 1 Agriculture products per UUA in Calabria Region and in DAQ (Source: Calabria Region regional Statistics centre).

\begin{tabular}{|c|c|c|c|}
\hline \multirow{2}{*}{$\begin{array}{l}\text { UAA (utilized } \\
\text { agricultural area) }\end{array}$} & \multicolumn{3}{|c|}{ Typical agricultural products per UUA } \\
\hline & Grapes & Fruit and vegetables & Olives \\
\hline Calabria & $13,825.81$ & $65,506.64$ & $165,297.28$ \\
\hline$\overline{\mathrm{DAQ}}$ & $1,362.19$ & $17,082.88$ & $24,317.94$ \\
\hline
\end{tabular}

Piana di Sibari produces $12 \%$ of all Italian citrus fruits and $50 \%$ of the total production of Clementine (Table 1).

In general by measuring agricultural GDP against the total wealth produced in all Italian provinces, it can be seen that Calabrian provinces are among the leaders.

In Italy quality agrifood districts are governed by national (D.Lgs.228/01) and regional law (Legge Regionale 16 aprile 2002) and take the form of public-private partnerships (PPP) and act to 
unite the urban and rural area. For the district to be created, in accordance with national and regional law, the minimum prerequisites must be present, such as:

- the realisation of one or more products which are similar, certified or protected pursuant to the EU or Italian law in force, which may be traditional or typical products, whose production is significant in terms of the regional agrifood economy.

- the presence of a consolidated system of contact among agricultural and agrifood companies.

- real interest from local institutions in the district in order to create cooperation and agreements with agricultural and agrifood companies.

In this study we have set ourselves the aim of verifying whether, besides the formalisation of the district by law, there are particular characteristics which are indicated in the scientific literature as typical of food hubs.

The competitive potential of companies arises from some structural features of the key production area: the produce of the single sectors, which is in some cases traditional and typical produce, is of a similar type and is certified and protected. There are also forms of integration among agricultural and agri-food companies.

There are also forms of integration between small agricultural companies, with an average size of 4 hectares and which represent $73 \%$ of producers, and large-scale companies [6].

\section{Conclusions: The Cooperative as Food hubs.}

A key role is played by the cooperative through which small agricultural companies transfer their produce to a single, large company which arranges to market the produce, purchase fertilisers, pesticides, and agricultural machinery. Collective purchases of these products enable prices to be paid which are well below what individual producers would pay by themselves and enable a marked lengthening of payment terms. All the produce from the cooperative's members is delivered to the refrigeration centre which has a covered surface area of 20,000 sq. m. and refrigeration capacity of 5,000 tonnes. The produce delivered is measured and put together in a uniform way in terms of its quality and size, with the allocation of codes or microchips which guarantee the possibility of tracing it back to the producer.

The end market for the cooperative is $90 \%$ covered by major retailers in Italy and Europe and the remaining $10 \%$ by the local market through the opening of direct sales points in the local area or town market and by online sales.

As for sales planning and transport logistics, the supply chains for the major retailers, such as Esselunga, Conad, COOP Switzerland and COOP Austria, send their own transport to the main company where all the produce is transferred, thus avoiding the dispersion and costs which would arise with the need to collect from a number of outlets.

Without this form of cooperation between the small agricultural companies and the larger, technologically advanced company, the large-scale retail market would be off limits to small producers. This depends not only on the limited quantities produced by small companies in the Sibari Agrifood District, which is insufficient to satisfy the requests of large retailers, but also on the certification prerequisites which large retailers require. In fact obtaining certification or applying innovative and environmentally friendly techniques for cultivation entails costs which are unsustainable for individual small producers. In particular the BRC standard, which is obtained by the larger company where all the logistical operations take place, is internationally recognised and is often an essential prerequisite which is requested by purchasers from large-scale distribution.

Another feature of this food-hub is that the biggest partner of the cooperative, where most of the logistic take place, can plan the production with buyer and producers in advance of the season making projections of product demand. This would allow producers to schedule planting and project sale for the season, but sometimes seasonal fluctuations is a challenge to overcome when there is too much fruit because of variation in demand, which, in turn, depends on consumers taste. 
At the same time small producers may make use of some environmentally friendly techniques tested by the biggest partner of the Cooperative through research work undertaken in connection with the University. For example, in order to reduce the number of anti-parasite treatments, the method of sexual confusion is adopted using pheromones, and, consequently, limiting the reproduction of harmful insects.

\section{Acknowledgements}

The synthetic work is still in progress within the CLUDs project granted by the 7th European Research Framework - Marie Curie IRSES actions, in order to build a conceptual framework of comparison among case studies analysed in San Diego (CA) and the logic of agrifood district implemented in Calabria Region under Rural Development Program of Calabria Region 2007-2013.

\section{References}

[1] D. Goodman: Rural Europe Redux? Reflection on Alternative Agro- food Networks and Paradigm Change. In: Sociologia Ruralis, 44, n1, (2004)

[2] Holloway et al. Beyond: The Alternative-Conventional Divide? Thinking Differently About Food Production-Consumption Relationships. In: D. Maye: Alternative Food Geographies. Bingley: Emerald, (2007)

[3] M. Ostrom: Community Supported Agricolture as an Agent of Change: Is it Working? In: C. Hirinchs, T. Lyson: Remaking the North American Food System (2007)

[4] J. Barham: Clarifying the Regional Food Hubs Concept. In: Regional Food Hub Resource Guide Rural Connections. United States Department of Agriculture Agricultural Marketing Service (2012)

[5] USDA Regional Food Hub Resource Guide Rural Connections. United States Department of Agriculture Agricultural Marketing Service (2012)

[6] Horst et al. Toward: A more expansive understanding of food hubs. In: Journal of Agriculture Food Systems and Community Development, 2 (1), (2011) 